\title{
Strengthening the Reporting of Nutritional Genomics Research to Inform Knowledge Translation in Personalized Nutrition
}

\author{
Justine R. Horne \\ Centre nutrition, santé et société (NUTRISS) - Institut sur la nutrition et les aliments fonctionnels (INAF), Université \\ Laval, Quebec City, QC, Canada
}

\author{
Keywords \\ Knowledge translation · Nutrigenomics · Personalized \\ nutrition · Precision nutrition · Nutrigenetics
}

\begin{abstract}
The ultimate goal of researching nutrigenetic interactions is to be able to provide individuals with genetically-tailored nutrition advice (when evidence is sufficient) in an effort to optimize health outcomes. Accordingly, original research often discusses the potential for the results to inform genetically-tailored nutrition advice. Despite this, many studies do not report their methods, results, and discussion in a manner that is conducive to knowledge translation. With several consumer nutritional genomics companies now offering genetic testing for personalized nutrition, proper reporting of nutritional genomics research for knowledge translation is of vital importance. Common reporting errors relate to SNP and genotype reporting, results lacking detail, consideration of linkage disequilibrium, mechanisms of action/functional SNPs, details of dietary intake, and sample reporting. Because of this, knowledge translation professionals may be unable or challenged in their attempt to use the findings from such research to inform clinical practice in nutritional genomics and personalized nutrition. The present article provides an overview of the issues at hand. It further pre-
\end{abstract}

karger@karger.com www.karger.com/lfg

Karger $\stackrel{\text { ' }}{5}$

BOPEN ACCESS
(C) 2021 The Author(s)

Published by S. Karger AG, Basel

This article is licensed under the Creative Commons AttributionNonCommercial-NoDerivatives 4.0 International License (CC BY NC-ND) (http://www.karger.com/Services/OpenAccessLicense) Usage and distribution for commercial purposes as well as any distribution of modified material requires written permission. sents a checklist as well as table and figure templates for researchers to use when reporting the results of original research in nutritional genomics to inform knowledge translation.

(C) 2021 The Author(s)

Published by S. Karger AG, Basel

\section{Introduction}

The STrengthening the REporting of Genetic Association studies (STREGA) guidelines form a best practice guide for reporting genetic association studies. In brief, these guidelines highlight specific reporting items for observational research in genetics. They include items such as "population stratification, genotyping errors, modelling haplotype variation, Hardy-Weinberg equilibrium, replication, selection of participants, rationale for choice of genes and variants, treatment effects in studying quantitative traits, statistical methods, relatedness, reporting of descriptive and outcome data," among others [1]. While genetic association studies are focused on correlations between genetic variation and health outcomes, nutrigenetics adds another layer with the addition of nutritional factors. In doing so, nutrigenetics helps to overcome a key limitation of genetic association studies, by considering environment/lifestyle factors in the prediction of health- 
related phenotypes [2]. The science of nutritional genomics aims to assess how nutrition interacts with genetics, thus influencing gene expression/function, protein levels, and metabolite levels, and how in turn this affects health and disease outcomes $[3,4]$. As such, while the key considerations presented in the STREGA guidelines generally remain relevant to observational nutritional genomics research, from a knowledge translation (KT) perspective, the field of nutritional genomics has additional considerations that are unique to this field. Moreover, while the STREGA guidelines are specific to reporting observational research, nutritional genomics research can be either observational $[5,6]$ or interventional $[7,8]$. Several reporting standards exist for biomedical research related to nutritional genomics including guidelines for reporting preclinical research, metabolomics, proteomics, and other omics studies [9]. However, guidelines for strengthening the reporting of nutritional genomics research, with an emphasis on informing KT, are needed.

The ultimate goal of nutritional genomics research is to personalize nutrition advice, based on individual genetic variation, when sufficient evidence exists. Personalized nutrition can be defined as the provision of dietary advice based on individual characteristics, including genetic variation, for health improvement and disease prevention $[3,10]$. Given that guidelines for reporting nutritional genomics research have yet to be established, items reported in nutritional genomics literature are variable. Notably, many studies do not provide sufficient information to adequately support KT - a process that aims to use knowledge gained from scientific research, and implement this knowledge in an effort to improve health outcomes [11]. Specific recommendations for reporting nutritional genomics research to support KT are needed. Therefore, this article aims to provide an overview of key reporting items, from a KT perspective, for nutritional genomics researchers to include when reporting the results of original nutritional genomics studies.

\section{Strengthening the Reporting of Nutritional Genomics Research to Support Knowledge Translation}

The reporting items detailed in the STREGA guidelines remain relevant to the field of nutritional genomics, especially for reporting observational nutritional genomics research. The following recommendations are intended to be reported in addition to the STREGA reporting items and are focused specifically on reporting items geared towards informing nutritional genomics KT.
From a KT perspective, healthcare professionals and the nutritional genomics industry are generally interested in offering nutrigenetic tests that will provide relevant recommendations that are applicable to a substantial proportion of the population. Therefore, priority may be placed on testing single nucleotide polymorphisms (SNPs) that are relatively common in the population. As such, it is important to report the genotype frequencies among a study population. In additional, KT professionals must be able to assess the generalizability of the findings and therefore the study sample should be clearly and thoroughly described. KT professionals may seek out studies with samples that are representative of the target population of a specific nutrigenomics test. In addition, the sex of the participants and any sex-specific analyses that were conducted should be reported, given that nutrigenetic interactions may vary depending on sex [10]. As such, it is possible and likely that as the science advances, certain personalized nutrition recommendations based on genetics will differ between men and women. More specific details on applying sex and gender in nutritional genomics research has been previously detailed elsewhere [10].

In terms of statistical analyses, nutrigenetic research often includes three-way interaction analyses for genetic variation, dietary factors, and subsequent health outcomes. Studies commonly report if the results from such interaction analyses are statistically significant (or not) but many do not report the specific genotype(s) connected to each dietary response. To strengthen the reporting of nutrigenetic research, original studies should clearly indicate the nutrition-related response among each genotype group. To that note, studies should also clearly report how genotypes were grouped. Depending on allele frequencies, some studies may compare minor allele carriers versus major allele homozygotes [12], while others may compare the three genotypes separately [13]. Failing to report genotype grouping and associated dietary responses can preclude KT experts from using this research to inform clinical practice as they may be unable to identify which type of nutrition advice should be provided to the heterozygote group. Specific details of genotype grouping should also be reported for polygenic interaction studies, and when nutrigenetic risk scores are developed, these should be clearly described with enough detail to allow them to be replicated and/or used in a clinical setting.

When reporting results, the importance of presenting both significant as well as null findings in nutrition literature is garnering meaningful attention in the nutrition 
Table 1. Table template for strengthening the reporting of nutrigenetic results for informing knowledge translation

\begin{tabular}{|c|c|c|c|c|c|c|c|c|}
\hline \multirow[b]{2}{*}{ Genotype for GENE, rs123456 } & \multicolumn{4}{|c|}{ Dietary intervention/association $\mathrm{A}^{1}$} & \multicolumn{4}{|c|}{ Dietary intervention/association $\mathrm{B}^{1}$} \\
\hline & AA & AG & GG & $p$ value & AA & $\mathrm{AG}$ & GG & $p$ value \\
\hline Change in health-related outcome ${ }^{2}$ & $\begin{array}{l}\text { Mean } \pm \\
\mathrm{SD}_{\mathrm{SSE}} \mathrm{a}\end{array}$ & $\begin{array}{l}\text { Mean } \pm \\
\text { SD/SE }\end{array}$ & $\begin{array}{l}\text { Mean } \pm \\
\text { SD/SE }\end{array}$ & $0 . \mathrm{xx}$ & $\begin{array}{l}\text { Mean } \pm \\
\mathrm{SD}_{\mathrm{SE}^{\mathrm{a}}}\end{array}$ & $\begin{array}{l}\text { Mean } \pm \\
\text { SD/SE }\end{array}$ & $\begin{array}{l}\text { Mean } \pm \\
\text { SD/SE }\end{array}$ & $0 . \mathrm{xx}$ \\
\hline \multicolumn{9}{|l|}{ or } \\
\hline Risk of health-related outcome ${ }^{2}$ & $\mathrm{RR}(\mathrm{CI})^{\mathrm{a}}$ & $\mathrm{RR}(\mathrm{CI})$ & $\mathrm{RR}(\mathrm{CI})$ & $0 . \mathrm{xx}$ & $\mathrm{RR}(\mathrm{CI})^{\mathrm{a}}$ & $\mathrm{RR}(\mathrm{CI})$ & $\mathrm{RR}(\mathrm{CI})$ & $0 . \mathrm{xx}$ \\
\hline
\end{tabular}

SD, standard deviation; SE, standard error; RR, relative risk; CI, confidence interval. ${ }^{1}$ Provide details of each dietary intervention (or placebo), including the amount of the dietary component consumed. ${ }^{2}$ Depending on the nature of the study, means and SD/SE or RR and CI should be reported as measures of precision for both statistically significant and non-significant results. ${ }^{a}$ Use superscripts to outline statistically significant nutrigenetic results; provide clear details of these results in a footnote (e.g., for AA genotypes, there was a statistically significant difference in [health-related outcome] depending on [dietary factor] intake, whereby consumption of [dietary factor and quantity] significantly reduced the risk of [health-related outcome]).

Fig. 1. Figure template for strengthening the reporting of nutrigenomics results for informing knowledge translation.

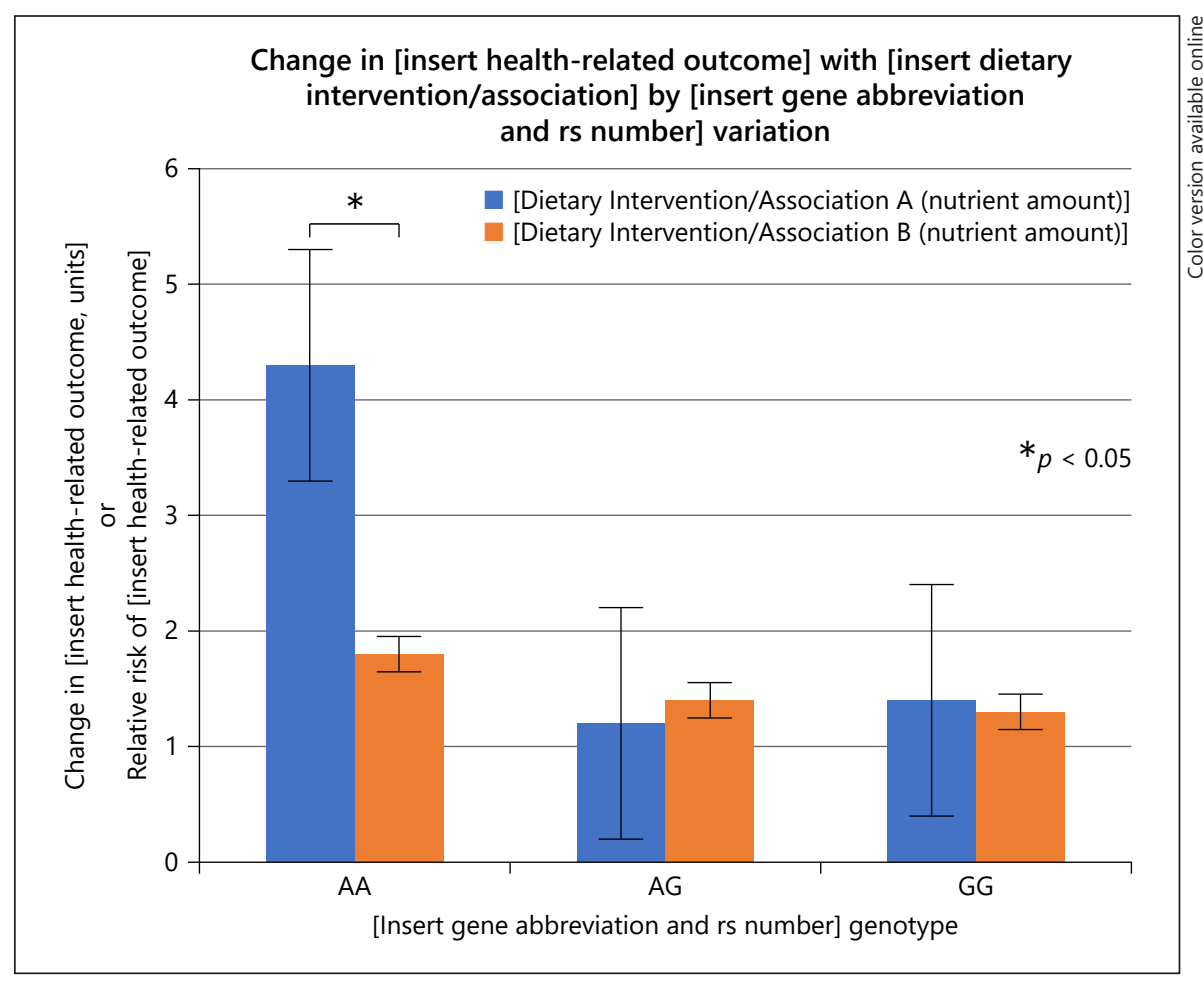

community $[14,15]$. This concept certainly remains important in the field of nutritional genomics, but further special considerations exist. Specifically, a list of the rs numbers for all the SNPs analyzed should be reported not just a list of SNPs with statistically significant nutrigenomics findings but also for those without significant findings. This is of great importance for $\mathrm{KT}$, as evidence grading typically includes an assessment of inconsistency $[16,17]$. If null findings are not reported, the body of knowledge may appear to be consistent and thus the evidence may appear to be strong, when in reality, this may not be the case.

Results should also clearly indicate the amount of the nutrient/dietary component that was (or was not) associ- 
Table 2. Strengthening the reporting of nutrigenetic studies to support knowledge translation: summary checklist

\begin{tabular}{|c|c|c|}
\hline $\begin{array}{l}\text { Manuscript } \\
\text { section }\end{array}$ & Item and description & $\begin{array}{l}\text { Page } \\
\text { number }\end{array}$ \\
\hline Methods & $\begin{array}{l}\text { Genotype grouping: } \\
\text { Describe or outline how genotypes were grouped for statistical analyses (e.g., minor allele carriers vs. } \\
\text { major allele homozygotes). }\end{array}$ & \\
\hline \multirow[t]{4}{*}{ Results } & $\begin{array}{l}\text { SNPs: } \\
\text { Indicate the rs number for all of the SNPs that were analyzed, and provide detailed results for } \\
\text { statistically significant and non-significant findings (using Table } 1 \text { and Fig. } 1 \text { as templates). }\end{array}$ & \\
\hline & $\begin{array}{l}\text { Study sample: } \\
\text { Provide specific details about the study sample to inform generalizability. }\end{array}$ & \\
\hline & $\begin{array}{l}\text { Genotype frequencies: } \\
\text { Report the frequencies of each genotype in the sample. }\end{array}$ & \\
\hline & $\begin{array}{l}\text { Measures of precision: } \\
\text { Report measures of precision with directions of the effect, such as RR and CI or means and SD/SE, } \\
\text { which can be used to calculate the coefficient of variation. }\end{array}$ & \\
\hline \multirow[t]{3}{*}{ Discussion } & $\begin{array}{l}\text { Sample relatedness: } \\
\text { For validation/replication studies, state if the sample consists of related individuals (to the original } \\
\text { study sample), and outline how this could impact the accuracy of the results. }\end{array}$ & \\
\hline & $\begin{array}{l}\text { Linkage disequilibrium: } \\
\text { Consider SNPs in strong or complete linkage disequilibrium when connecting the results of one study } \\
\text { with the results of another study/other studies. }\end{array}$ & \\
\hline & $\begin{array}{l}\text { Mechanism of action/functional SNPs: } \\
\text { Describe what is known about systems genetics and the physiological mechanism of action for any } \\
\text { statistically significant nutrigenetic results. }\end{array}$ & \\
\hline
\end{tabular}

ated with a genotype-specific effect. To inform nutritional genomics KT, experts must develop specific dietary recommendations, highlighting the need to clearly report specific nutrient dosages (for interventional research) or mean/median intakes (in observational research).

It is further important to report a measure (or multiple measures) of precision, for both statistically significant and non-significant findings. Evidence synthesis methods require a critical evaluation of the quality of research, while comparing the results of different studies. For example, the Grading of Recommendations, Assessment, Development and Evaluation (GRADE) approach is commonly used for developing recommendations for clinical practice; this approach includes the category "imprecision" as a key component of the established evidence grading method [16]. Measures such as relative risk and confidence intervals or means and standard deviation (used to calculate coefficients of variation) can be used to assess precision and should be reported in nutritional genomics studies. This data further provides important information on the direction and magnitude of the effect.

Table 1 and Figure 1 depict templates that can be used to ensure that results (both significant and non-significant) are adequately reported to inform KT. To reiterate, reporting non-significant findings is of vital importance as these results can inform inconsistencies in the literature, which may downgrade levels of evidence [16] and thus preclude recommendations for including such nutrigenetic interactions in clinical practice. In cases where authors are limited in the number of tables/figures that can be reported in the main manuscript document, sup- 
plementary files should be published. It is also important to note that reporting data only in graph format, without presenting the numerical results, does not provide sufficient detail to inform evidence synthesis, as means and standard deviation/error or relative risk and confidence intervals are needed to assess a study's precision.

There are also important considerations for a study's discussion. The STREGA guidelines recommend reporting whether or not a study replicates findings of previous work [1]. This remains an important consideration for nutritional genomics research; such research should further consider linkage disequilibrium (LD). The results from one study could replicate the findings from another study in which a different SNP was assessed, but one that is in strong or complete LD with the replication study. For example, studies assessing FTO rs1558902 should consider the results of studies assessing FTO rs9939609 as a component of the discussion section of the manuscript, given that these two SNPs are in strong LD [18]. For KT, nutritional genomics research should also consider the population of the original study and of subsequent validation studies. When the original study sample and the sample of subsequent validation studies consist of unrelated individuals, our confidence of the accuracy of the results improves [2, 19]. The discussion should also provide an overview of the potential mechanism of action for significant findings, for example by pointing to gene expression, proteomics, metabolomics, and other systems genetics research [19]. The consideration of functional SNPs is salient as it provides insights into whether the SNP has been demonstrated to have a functional role; if so, this can enhance our confidence in the significant findings. In cases where systems genetics are not well understood and a mechanism of action has not been demonstrated, it is possible that the molecular and clinical traits are independent, with confounding factors influencing the results [19]. In cases where the underlying mechanism of action for a nutritional genomics interaction is well understood, recommendations for clinical practice may be stronger, or evidence may be considered higher quality from a scientific validity perspective [20].

These reporting items have been summarized in the checklist in Table 2.

\section{Conclusion}

This editorial provides a guide for proper reporting of nutrigenetic research to inform KT. These guidelines are relevant to nutritional genomics researchers as well as peer-reviewers and editors to help ensure that published research provides sufficient detail to have a pragmatic impact. Developing an extension of the STREGA guidelines [1] for both observational and interventional nutrigenomics research is an important next step for strengthening the reporting of nutrigenetic research, promoting KT and thus informing clinical practice. The present editorial can be used as guidance to build such a framework. As research continues to progress, evidence synthesis will only become an increasingly common and important endeavour in order to guide clinical practice in nutritional genomics and personalized nutrition.

\section{Conflict of Interest Statement}

The author has no conflicts of interest to declare.

\section{Funding Sources}

J.R. Horne was supported through postdoctoral fellowships from the Canadian Institutes of Health Research (CIHR), Centre Nutrition, Santé et Société (NUTRISS), and the Institut sur la nutrition et les aliments fonctionnels (INAF).

\section{Author Contributions}

J.R. Horne was responsible for conceptualizing, writing, and revising the article.

\section{References}

Strengthening Nutritional Genomics

Reporting for KT
1 Little J, Higgins JP, Ioannidis JP, Moher D, Gagnon F, von Elm E, et al.; STrengthening the REporting of Genetic Association Studies. STrengthening the REporting of Genetic Association studies (STREGA): an extension of the STROBE statement. PLoS Med. 2009 Feb; 6(2):e22.

2 Wray NR, Yang J, Hayes BJ, Price AL, Goddard ME, Visscher PM. Pitfalls of predicting complex traits from SNPs. Nat Rev Genet. 2013 Jul;14(7):507-15.

3 Ferguson LR, De Caterina R, Görman U, Allayee H, Kohlmeier M, Prasad C, et al. Guide and Position of the International Society of Nutrigenetics/Nutrigenomics on Personalised Nutrition: Part 1 - Fields of Precision Nutrition. J Nutrigenet Nutrigenomics. 2016; 9(1):12-27. 
4 Ferguson JF, Allayee H, Gerszten RE, Ideraabdullah F, Kris-Etherton PM, Ordovás JM, et al.; American Heart Association Council on Functional Genomics and Translational Biology, Council on Epidemiology and Prevention, and Stroke Council. Nutrigenomics, the Microbiome, and Gene-Environment Interactions: New Directions in Cardiovascular Disease Research, Prevention, and Treatment: A Scientific Statement From the American Heart Association. Circ Cardiovasc Genet. 2016 Jun;9(3):291-313.

5 Chen Y, Estampador AC, Keller M, Poveda A, Dalla-Riva J, Johansson I, et al. The combined effects of FADS gene variation and dietary fats in obesity-related traits in a population from the far north of Sweden: the GLACIER Study. Int J Obes. 2019 Apr;43(4):808-20.

6 Bouchard-Mercier A, Godin G, Lamarche B, Pérusse L, Vohl MC. Effects of peroxisome proliferator-activated receptors, dietary fat intakes and gene-diet interactions on peak particle diameters of low-density lipoproteins. J Nutrigenet Nutrigenomics. 2011;4(1): 36-48.

7 Vallée Marcotte B, Guénard F, Lemieux S, Couture P, Rudkowska I, Calder PC, et al. Fine mapping of genome-wide association study signals to identify genetic markers of the plasma triglyceride response to an omega-3 fatty acid supplementation. Am J Clin Nutr. 2019 Jan;109(1):176-85.
8 Itariu BK, Zeyda M, Hochbrugger EE, Neuhofer A, Prager G, Schindler K, et al. Long-chain n-3 PUFAs reduce adipose tissue and systemic inflammation in severely obese nondiabetic patients: a randomized controlled trial. Am J Clin Nutr. 2012 Nov;96(5): 1137-49.

9 Kaput J, Perozzi G, Radonjic M, Virgili F. Propelling the paradigm shift from reductionism to systems nutrition. Genes Nutr. 2017 Jan 25; 12:3.

10 Corella D, Coltell O, Portolés O, Sotos-Prieto M, Fernández-Carrión R, Ramirez-Sabio JB, et al. A Guide to Applying the Sex-Gender Perspective to Nutritional Genomics. Nutrients. 2018 Dec;11(1):4.

11 Graham ID, Logan J, Harrison MB, Straus SE, Tetroe J, Caswell W, et al. Lost in knowledge translation: time for a map? J Contin Educ Health Prof. 2006;26(1):13-24.

12 Roke K, Mutch DM. The role of FADS1/2 polymorphisms on cardiometabolic markers and fatty acid profiles in young adults consuming fish oil supplements. Nutrients. 2014 Jun;6(6):2290-304

13 Dumont J, Goumidi L, Grenier-Boley B, Cottel D, Marécaux N, Montaye M, et al. Dietary linoleic acid interacts with FADS1 genetic variability to modulate HDL-cholesterol and obesity-related traits. Clin Nutr. 2018 Oct; 37(5):1683-9.
14 Garza C, Stover PJ, Ohlhorst SD, Field MS, Steinbrook R, Rowe S, et al. Best practices in nutrition science to earn and keep the public's trust. Am J Clin Nutr. 2019 Jan;109(1):22543.

15 Antin PB, Baldwin TO, Freeze HH, Haywood JR, Simon SI, Brunner D, et al. Enhancing research reproducibility: Recommendations from the Federation of American Societies for Experimental Biology. FASEB; 2016. p. 16.

16 GRADE handbook [Internet]. [cited 2020 Sep 29]. Available from: https://gdt.gradepro.org/ app/handbook/handbook.html.

17 PEN. PEN Evidence Grading Checklist [Internet]. 2010. Available from: http://www. pennutrition.com/pdf/PEN_Evidence_ Grading_Dec_2010.pdf.

18 Zhang X, Qi Q, Zhang C, Smith SR, Hu FB, Sacks FM, et al. FTO genotype and 2-year change in body composition and fat distribution in response to weight-loss diets: the POUNDS LOST Trial. Diabetes. 2012 Nov; 61(11):3005-11.

19 Civelek M, Lusis AJ. Systems genetics approaches to understand complex traits. Nat Rev Genet. 2014 Jan;15(1):34-48.

20 Grimaldi KA, van Ommen B, Ordovas JM, Parnell LD, Mathers JC, Bendik I, et al. Proposed guidelines to evaluate scientific validity and evidence for genotype-based dietary advice. Genes Nutr. 2017 Dec;12(1):35. 